\title{
Utilização dos recursos naturais por comunidades humanas do Parque Ecoturístico do Guamá, Belém, Pará ${ }^{1}$
}

\author{
Ana Sílvia Sardinha RIBEIRO²; Maria das Dores Correia PALHA²; Manoel Malheiros TOURINHO²; \\ ChristinaWippich WHITEMAN²; Alanna do Socorro Lima da SILVA²
}

\begin{abstract}
RESUMO
O trabalho apresenta dados sobre o uso dos recursos naturais por populaçôes humanas em pequenas comunidades (vilas) localizadas no entorno $(\mathrm{n}=6)$ e no interior $(\mathrm{n}=1)$ do Parque Ecoturístico do Guamá $(\mathrm{PEG})$, visando avaliar os impactos sobre a fauna e flora local, ante a implantação de um projeto de infra-estrutura rodoviária local. A metodologia consistiu da aplicação de dois modelos de questionários. Um direcionado a pessoas-chave, como: moradores mais antigos, presidentes de associaçôes, agentes de saúde, etc, e o outro aplicado aleatoriamente aos adultos locais. Buscou-se atingir pelo menos $50 \%$ das famílias das pequenas localidades ( $\leq 10$ famílias) e 10-15\% no caso de comunidades maiores ( $\geq 11$ famílias). Em todos os casos é realizado o extrativismo da fauna e flora, principalmente com o objetivo de subsistência. As espécies mais caçadas foram Agouti paca, Dasyprocta agouti, Nasua nasua, Euphractus sexcintus e Hydrochaeris hydrochaeris. A complementação da renda familiar através do comércio de caça sob encomenda é realizada em todas as comunidades estudadas. Frutíferas como Euterpe oleracea Mart., Musa spp e Theobroma cacao foram encontradas em 100\% das comunidades ( $\mathrm{n}=7$ ). Plantas medicinais são rotineiramente cultivadas e empregadas. As espécies madeireiras exploradas são utilizadas com o objetivo de produção de carvão, construção de casas e de meios de transporte, predominando o Inga edulis, Virola surinamensis (Rol.) Warb e Simaruba amara (Aubl.). O trabalho discute os resultados sob o aspecto da implantação do projeto viário, oferecendo recomendações para a minimização dos impactos do mesmo sobre a fauna, a flora e o modo tradicional de vida das comunidades.
\end{abstract}

\section{PALAVRAS CHAVE}

Comunidades rurais, extrativismo, recursos naturais, estradas

\section{Utilization of natural resources by the buman communities of the Guamá Ecotouristic Park, Belém, Pará}

\begin{abstract}
This work shows data about the use of natural resources by the human population located in $(n=1)$ and around $(n=6)$ the Guamá Ecotouristic Park (GEP), in order to evaluate the impact on the local fauna and flora in view of the project for constructing a road through the park. The methodology utilized in this community study was the application of two different types of questionnaires. One was directed to key persons such as old residents, presidents of associations, health agents, etc., and the other was randomly applied to local adults. We attempted to approach at least $50 \%$ of the families in the small villages ( $\leq 10$ families) and $10-15 \%$ in the larger communities ( $\geq 11$ families). In all cases, there was flora and fauna extractivism, especially for subsistence. The most hunted species were the Agouti paca, Dasyprocta agouti, Nasua nasua, Euphractus sexcintus and Hidrochaeris hidrochaeris. All the communities studied complement their family income by hunting wildlife on order. Fruit trees such as Euterpe oleracea Mart., Musa spp and the Theobroma cacao were found in 100\% of the communities $(n=7)$. Medicinal plants are cultivated and used routinely. Timber species such Inga edulis, Virola surinamensis (Rol.) Warb e Simaruba amara (Aubl.) are used for charcoal production, house building and transportation means. We discuss the results relating to construction of the road, and make recommendations for reducing the impact on the fauna, the flora and the traditional livelihood of the communities.
\end{abstract}

\section{KEYWORDS}

Rural communities, extractives, natural resources, roads 


\section{INTRODUÇÃO}

As transformações impostas ao meio ambiente pela ocupação humana implicaram no fato de que as cidades e suas respectivas vias de acesso assumissem um cenário antagônico ao meio natural, induzindo desequilíbrios sociais e ecológicos, o que foi particularmente notório a partir da revolução industrial. Segundo Palha et al. (2002), na complexa equação "desenvolvimento versus conservação ambiental”, a necessidade de rodovias para fluxo de pessoas e produtos esbarra nas implicaçóes à paisagem e ao equilíbrio ecológico, sem falar nos impactos para as populaçōes tradicionais que vivem nessas áreas. Ainda segundo os autores, atualmente a legislação ambiental está se adequando a considerar os impactos das obras de infra-estrutura necessárias à expansão da economia dos centros urbanos ou daquelas relacionadas à exploração de recursos naturais, especialmente de grandes e médios portes.

Para Bodmer \& Penn Jr. (1997), a conservação das florestas tropicais é um dos maiores desafios da humanidade, devido ao delicado equilíbrio que precisa ser estabelecido entre um ecossistema complexo e frágil, de grande diversidade de espécies e altos índices de endemismo, e uma população rural pobre, que necessita de um futuro ecologicamente sustentável e economicamente satisfatório.

A busca de alternativas de valorização econômica do meio rural, que limitem o desmatamento, levou a que se desse um interesse especial ao extrativismo. Há pelo menos uma década, essa atividade é objeto de diversas pesquisas, tanto sobre sua viabilidade ecológica como sobre sua inserção socioeconômica (Bahri, 2000).

A ação antrópica, caracterizada especialmente pela caça, exploração madeireira e o desmatamento, exerce efeitos variados sobre as densidades das espécies animais. A caça acarreta diminuição das densidades das espécies de maior porte, que são mais visadas. Se a pressão de caça for muito intensa, os animais com baixas densidades e baixas taxas reprodutivas poderão desaparecer, conforme observado por Peres (1990) em primatas no oeste da Amazônia. Já a exploração madeireira, por alterar substancialmente a estrutura da floresta, provoca o aumento das espécies que se adaptam a ambientes perturbados. Alguns herbívoros, como os veados (Mazama spp.), são beneficiados pela maior disponibilidade de gramíneas que surgem nas clareiras (Dourojeanni, 1985), enquanto que pequenos primatas são beneficiados pelo aumento de florestas secundárias (Jonhs \& Skorupa, 1987). Por outro lado, espécies mais sensíveis a alteraçōes de habitat têm suas densidades reduzidas.

Quando consideramos que essa alteração de habitat advém de projetos de infra-estrutura de grande porte, como construção de estradas, os impactos também são macros e vêm em cadeia. Assim como alguns grupos animais têm suas populações reduzidas, outros grupos, como os insetos, se multiplicam. Silva \& Sá (1999) relatam o surgimento de 171 mil casos de malária durante a implantação do eixo da BR-364 no estado de Rondônia, além da invasão de gafanhotos, através da clareira aberta para a construção da estrada. Tal obra provocou ainda um acelerado desmatamento e mudanças nas atividades locais, causando grandes desequilíbrios ambientais e sócio-econômicos.

Shanley et al. (1997) citam que espécies da fauna silvestre, como caititu (Tayassu tajacu), queixada (Tayassu pecari), anta (Tapirus terrestris), paca (Agouti paca), cutia (Dasyprocta agouti), papagaio (Amazona sp), araras (Ara sp.), dentre outras, dependem muito das frutas; portanto, as florestas que possuem muitas frutíferas que florescem e frutificam durante várias épocas do ano são capazes de abrigar muitos animais. Com base nisso, sugerem que as populações humanas que queiram aumentar a oferta de espécies de caça em suas florestas, podem manejar e proteger as frutíferas a elas relacionadas, aumentando indiretamente sua própria diversidade alimentar. Trabalhos realizados por Palha et al. (1999) em comunidades de várzea da Amazônia brasileira, onde a caça é uma atividade freqüente, relatam ser ainda atual a concepção de que a fauna é um recurso inesgotável, embora a maior parte dos entrevistados reconheça que havia maior fartura de caça em épocas passadas. Os autores citam as diferentes formas de uso das espécies da fauna por parte destas comunidades, destacando o uso alimentar, o "xerimbabismo" (animais de estimação) e o uso terapêutico. King (1999) também associa que a fauna silvestre em muitas partes do mundo declinou drasticamente, encontra-se ameaçada ou se extinguiu, como resultado da perda de habitat ocasionada pela expansão humana, ou, como resultado da sobre-exploração, freqüentemente, de produtos comerciais.

O extrativismo da fauna silvestre para o "caboclo" amazônico faz da fauna um importante recurso da floresta, visto que, sua exploração constitui-se numa atividade rotineira, sendo importante geradora de renda às populações da região. No entanto, o subdesenvolvimento existente da maioria das comunidades amazônicas nutre a pobreza e o abandono, e a conseqüente exploração irracional da fauna; apesar das populações nativas interagirem com a natureza de uma forma culturalmente mais harmônica. Ou seja, a caça de subsistência passa a ser predatória, sem um manejo adequado para a exploração sustentável dos recursos faunísticos, fomentando assim atividades ilegais de comércio de animais e seus produtos.

A exploração dos recursos florestais com fins madeireiros é prática comum e rotineiramente citada, contudo deve ser destacado o uso de frutíferas e plantas medicinais, por comunidades tradicionais. Segundo Lameira (2004), essas plantas são usadas há séculos pelos povos da floresta, tendo nas tradições populares a comprovação da sua eficácia

Este trabalho foi realizado a partir de dados resultantes dos estudos relacionados ao "Programa de Aproveitamento Científico da Fauna e Flora da Alça Rodoviária de Belém”, convênio SETRAN/UFRA/FUNPEA, com o objetivo de levantar 
informaçōes sobre o uso dos recursos naturais por populaçōes humanas em pequenas comunidades (vilas) localizadas no entorno e no interior do Parque Ecoturístico do Guamá (PEG), visando avaliar os impactos sobre a fauna e flora local, ante a implantação de um projeto de infra-estrutura rodoviária local.

\section{MATERIAL E MÉTODOS}

Foram coletados dados no período de janeiro a julho de 2002, em sete comunidades, sendo uma (Ponta Negra) localizada dentro da área do Parque Ecoturístico do Guamá (PEG) e seis (Abacatal - $1^{\circ} 25^{\prime} 18,7 \mathrm{~S}$ e $48^{\circ} 20^{\prime} 59,0^{\prime \prime} \mathrm{W}$, Flexal - $1^{\circ} 28^{\prime}$ $39,3 \mathrm{~S}$ e $48^{\circ} 12^{\prime} 38,9^{\prime \prime W}$, Santo Amaro - 1'26’43,7" S e $48^{\circ} 14^{\prime} 46,3^{\prime \prime W}$, Maravilha - $1^{\circ} 24^{\prime} 55.8^{\prime \prime}$ 'S e $48^{\circ} 21^{\prime} 02,4^{\prime \prime W}$, Tacajós - 1o $28^{\prime} 59,4^{\prime} \mathrm{S}$ e $48^{\circ} 11^{\prime}$ 08,6"W e Tayassu-í $1^{\circ} 24^{\prime} 29,2^{\prime \prime} \mathrm{Se} 48^{\circ} 11^{\prime} 08,6^{\prime \prime} \mathrm{W}$ ) localizadas no entorno do Parque.

O Parque Ecoturístico do Guamá (PEG) possui área de 7.787,33 ha, sendo originário da antiga Fazenda Guamá, pertencente à Pirelli - Cia. Industrial Brasileira. Situa-se na região metropolitana de Belém e seu principal acesso dista aproximadamente $23 \mathrm{~km}$ do centro da cidade. Estende-se por uma faixa de $18 \mathrm{~km}$ ao longo da margem direita do rio Guamá, entre os rios Caraparu a Leste e Uriboquinha a Oeste. Situa-se contíguo com a Área de Proteção Ambiental de Belém (APABelém), a Oeste, e suas terras abrangem cinco municípios: Belém, Ananindeua, Marituba, Benevides e Santa Izabel do Pará.

A metodologia utilizada para o estudo de comunidades consistiu da aplicação de questionários semi-estruturados (dois tipos) previamente elaborados, em abordagem metodológica de Diagnóstico Rural Rápido (DRR), totalizando 32 questionários aplicados, correspondendo a 13\% das famílias entrevistadas. Um dos questionários, denominado "QUESTIONÁRIO 3: TIPOLOGIA DA COMUNIDADE", foi direcionado a pessoas-chave das comunidades, tais como: moradores mais antigos, presidentes de associações, agentes de saúde, chefes de família, etc. Um outro, denominado "QUESTIONÁRIO 4: PARA COMUNIDADES-DOMICÍLIOS”, foi aplicado aleatoriamente aos moradores locais eventualmente disponíveis. Atingiu-se pelo menos $50 \%$ das famílias das pequenas comunidades ( $\leq 10$ famílias) e $10-15 \%$ ( $\geq 11$ famílias) no caso de comunidades maiores,. Também foram feitos registros fotográficos, obtenção de coordenadas geográficas com Sistema de Posicionamento Global (GPS) e tomada de depoimentos de moradores. Foram realizadas visitas prévias às localidades para a identificação das pessoas-chave e para coleta de informaçôes sobre a comunidade e acertos quanto ao apoio logístico. Os dados obtidos com o questionário foram planificados através do Programa Excel e analisados mediante estatística descritiva.

\section{RESULTADOS E DISCUSSÃO}

A utilização dos recursos naturais é prática comum em todas as comunidades, havendo uso mais restrito pela comunidade de Tacajós, o que se atribui que seja em virtude da origem da população local, historicamente colonizada por trabalhadores do INCRA.

$\mathrm{Na}$ comunidade localizada dentro do PEG, denominada Ponta Negra, foram levantados dados totalizando quatro questionários aplicados.

Esta comunidade está localizada na margem esquerda do rio Guamá e a 100 m da maior ponte da Alça Rodoviária, a Ponte Guamá-Acará. É uma comunidade que vive do extrativismo vegetal e animal, sendo muito forte a prática de caça, tanto com o objetivo alimentar como para a venda, a qual, segundo relato dos entrevistados, ocorre sempre em função de encomendas ou necessidades da família. Resultados do estudo estão sumarizados na Tabela 1 .

As espécies da fauna silvestre mais caçadas pela comunidade localizada dentro do Parque Ecoturístico do Guamá foram a paca (Agouti paca), cutia (Dasyprocta agouti), quati (Nasua nasua), preguiça-comum (Bradypus variegatus), tatu-peba (Cabassous unicinctus), caitetu (Tayassu tajacu), jacaré-tinga (Caiman crocodilus crocodilus), veado-vermelho (Cabassous unicintus) e o peixe-boi (Trichechus inunguis).

Uma observação importante quanto ao consumo de caça por essa comunidade é que a caça de primeira, ou seja, a mais procurada em função do sabor e valor comercial, como a paca, é destinada para comercialização, enquanto a comunidade consome a chamada caça "de segunda", como o quati e a preguiça, com o preço dos animais variando de $\mathrm{R} \$ 5,00$ a $\mathrm{R} \$ 10,00$.

As comunidades do entorno, em número de seis, foram estudadas totalizando 28 questionários aplicados. Os dados com informaçôes sócio-econômicas também estão representados na Tabela 1.

Os principais recursos faunísticos e florestais utilizados pelas comunidades do entorno do PEG podem ser observados na Figura 1 e Tabela 2, respectivamente.

Os animais, além de serem utilizados como fontes de proteína, servem como "xerimbabo" e na terapêutica, através, principalmente, do uso da banha de espécies como a mucura (Didelphis marsupialis), jibóia (Boa constrictor), tatu-bola (Cabassous unicinctus) e camaleão (Iguana iguana), sendo as duas primeiras espécies citadas por $90 \%$ das comunidades, tornandose um indicador para o desenvolvimento de pesquisas na área farmacológica e biomédica. A comunidade de Tacajós foi a única que não utilizou produtos animais na terapêutica, fato esse que foi associado à presença de um posto de saúde, com atendimento diário. Além disso, parte da população lá estabelecida é formada 
Tabela 1 - Características gerais das comunidades do Parque Ecoturístico do Guamá. Região Metropolitana de Belém, Pará.

\begin{tabular}{|c|c|c|c|c|c|c|c|}
\hline & Abacatal & Flexal & Sto. Amaro & Maravilha & Tacajós & Tayassu-í & Ponta Negra \\
\hline № Famílias & 52 & 15 & 8 & 68 & 103 & 0 & 6 \\
\hline № Domicílios & 48 & 18 & 8 & 62 & 0 & 30 & 6 \\
\hline Escola & Sim & Não & Sim & Sim & Sim & Sim & Não \\
\hline Posto de Saúde & Não & Não & Não & Não & Sim & Não & Não \\
\hline Agente de Saúde & Não & Sim & Não & Sim & Sim & Sim & Não \\
\hline Água & $\mathrm{I} / \mathrm{P}$ & $\mathrm{R}$ & I & $E / P / I$ & $E / I$ & $E / P$ & $\mathrm{R}$ \\
\hline Fossa & FN & $\mathrm{FN}$ & FN & FS/FN & $\mathrm{FS} / \mathrm{FN}$ & FS/FN & $\mathrm{FN}$ \\
\hline Eletricidade & Sim & Não & Não & Sim & Sim & Sim & Não \\
\hline Transporte & Não & Não & Não & Sim & Sim & Sim & Não \\
\hline Organização Social & Sim & Sim & Não & Sim & Sim & Sim & Não \\
\hline Parcerias & Sim & Não & Prefeitura & Não & Sim & Sim & Não \\
\hline Título da Terra & Comunitário & Sem título & Individual & Comunitário & Provisório & Não & Não \\
\hline Religião & Católica & Católica & Católica & Católica & Católica/ Evangélica & Católica & Católica \\
\hline Economia & Ex & EX/A & Ro/A & Ro & O/Ro/A & $\mathrm{C} / \mathrm{Ro} / \mathrm{A}$ & Ex \\
\hline Renda Familiar Média & $\mathrm{R} \$ 200,00$ & $\mathrm{R} \$ 200,00$ & $\mathrm{R} \$ 162,50$ & $\mathrm{R} \$ 266,66$ & $\mathrm{R} \$ 324,50$ & $\mathrm{R} \$ 533,00$ & $\mathrm{R} \$ 200.00$ \\
\hline
\end{tabular}

Abreviaturas: $\mathrm{I}=$ igarapé, $\mathrm{P}=$ poço $(\mathrm{P}), \mathrm{R}=$ rio, $\mathrm{E}=$ encanada, $\mathrm{FN}=$ fossa negra, $\mathrm{FS}=$ fossa sanitária, $\mathrm{E}=$ extrativismo, $\mathrm{A}=$ aposentadoria, $\mathrm{R}=$ roça, $\mathrm{C}=$ comércio, $0=$ olaria.

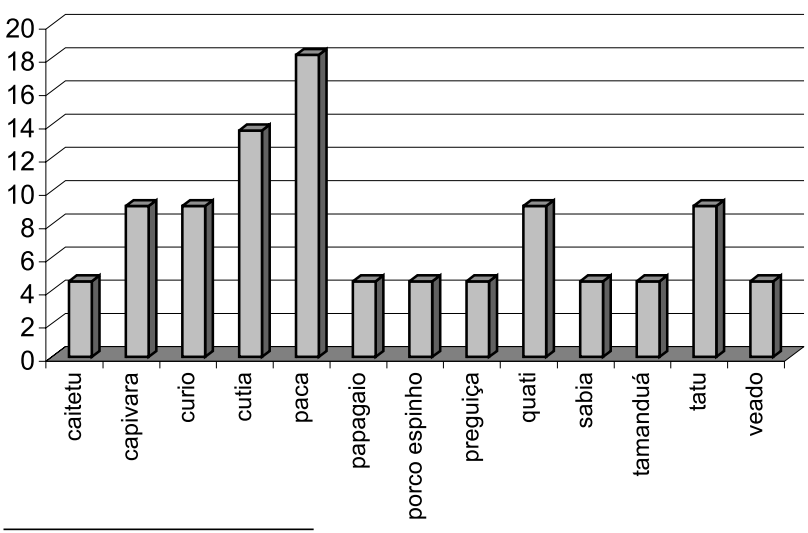

Figura 1 - Distribuição percentual dos animais silvestres mais caçados nas comunidades estudadas.

por migrantes mais recentes, originários especialmente da região Nordeste do Brasil, conforme histórico de assentamento desta comunidade.

A caça é uma atividade comum em todas as comunidades, contudo foram observados distintos objetivos com relação a essa prática, que vão do uso alimentar, "xerimbabismo" ao comércio de animais e/ou seus produtos, caracterizando a atividade ilegal. Elabras (2002) classifica a prática de comércio ilegal exercida por populações tradicionais como "tráfico para subsistência", aquele realizado nas beiras das estradas pela população local, visando seu próprio sustento. $\mathrm{Na}$ maior parte dos casos, esse comércio a varejo está intrinsecamente ligado aos problemas sociais e educacionais que o Brasil enfrenta e à má distribuição de renda.
Tabela 2 - Espécies madeireiras, fruteiras e plantas medicinais mais utilizadas nas comunidades estudadas do Parque Ecoturístico do Guamá. Região Metropolitana de Belém, Pará.

\begin{tabular}{cc}
\hline NOME VULGAR & NOME CIENTíFICO \\
\hline Ingá & Inga paraensis Ducke \\
\hline Virola & Virola surinamensis (Rol.) Warb. \\
\hline Marupá & Simaruba amara (Aubl.) \\
\hline Mauba & Licaria mahuba (Kuhlm. \& Samp) Karsterm. \\
\hline Tapiririca & Tapirira guianensis Aubl. \\
\hline Açaí & Euterpe oleracea Mart. \\
\hline Banana & Musa sapientum L. \\
\hline Cacau & Theobroma cacao L. \\
\hline Castanha do pará & Bertholletia excelsa Bonpl. \\
\hline Hortelã & Mentha arvensis L. Var Piperita \\
\hline Anador & Justicia sp Anon. \\
\hline Erva-cidreira & Lippia alba \\
\hline Arruda & Ruta graneolens L. \\
\hline Pariri & Arrabidaea chica \\
\hline Marupá & Simaruba amara (Aubl.) \\
\hline
\end{tabular}

Outra prática também realizada por essas comunidades é o "tráfico sob encomenda", onde os animais são capturados a pedido de terceiros. No caso deste estudo, a maioria das encomendas sempre teve cunho alimentar.

Foi possível observar que as populaçōes que vivem do extrativismo têm dificuldade em entender que a caça que não 
tenha como objetivo a subsistência, é considerada crime ambiental (Lei 9.605/98) e que eles tornam-se cúmplices no tráfico de animais silvestres, a partir das atividades que envolvem a captura dos animais e a venda dos mesmos.

O uso afetivo desses animais também foi observado, mas não é uma característica muito marcante, principalmente em função da presença constante de policiais do Batalhão de Polícia Ambiental na área. Os grupos de animais mais apreciados para uso afetivo são: psitacídeos e passeriformes, com destaque para bicudos (Oryzoborus crassirostris) e curiós (Oryzoborus sp.). As comunidades manifestaram a tentativa de criação de animais silvestres em cativeiro, com o objetivo de "xerimbabo", sendo preferidos para essa experiência, passeriformes, preguiças e psitacídeos. Os entrevistados comungam da mesma opinião quanto à diminuição dos recursos faunísticos, que aumenta a dificuldade de sobrevivência destas famílias na área. Relatos sobre a observação quanto à diminuição de espécies da fauna silvestre, também foram citados por Palha et al. (1999) e King (1999).

As comunidades se ressentem com a presença constante da polícia ambiental na área, dificultando as atividades de extrativismo dos produtos da fauna e flora, visto que essas populaçôes têm dificuldade para entender a proibição da extração de produtos, por serem atividades que eles vêm desenvolvendo tradicionalmente ao longo de sua história. A polícia relata que os extrativistas locais não usam os recursos somente para subsistência, extraindo além do necessário, para comercializar ilegalmente.

No item educação, estima-se que $80 \%$ das crianças das comunidades estudadas freqüentam a escola. Observa-se que somente na Comunidade de Tacajós há algum tipo de preocupação quanto à conservação do meio ambiente, sendo realizadas atividades na Semana do Meio Ambiente e aleatoriamente durante o ano letivo, com exercícios ligados ao tema, como: preservação dos rios, importância dos animais para a natureza, etc. Nesta comunidade há uma experiência de parceria com a Polícia Civil, através de um trabalho de educação ambiental nas escolas, resultando na diminuição do uso de baladeiras por crianças e adolescentes, objetivando favorecer o restabelecimento da avifauna local. Contudo não há um trabalho incisivo e rotineiro de educação ambiental na maioria das escolas.

A presença de fruteiras tanto para exploração comercial quanto para o consumo familiar é característico das populações amazônicas. Neste estudo não foram realizados inventários dos quintais agroflorestais, havendo somente o registro de dados coletados nas entrevistas e das observações aleatórias in loco. Ressaltam-se os relatos quanto à importância das fruteiras e sua diversidade para essas populaçōes, surgindo tanto como alternativa e/ou complemento alimentar, como atrativo para a fauna local.

Fato que corrobora o postulado por Shanley et al. (1997) de que muitas espécies de caça são frugívoras, como os cervídeos que têm mais de $80 \%$ de sua dieta constituída por frutas, podendo ser adotado um manejo para proteger e propagar as frutíferas estratégicas, aumentando assim a oferta alimentar para os animais e os homens, neste caso, em termos de frutas e caças.

O uso de plantas medicinais é prática comum nas comunidades tradicionais da Amazônia e, segundo Lameira (2004), essas plantas são usadas há séculos pelos povos da floresta, tendo nas tradições populares a comprovação da sua eficácia. Nas comunidades estudadas foi observada essa prática, sendo o cultivo das mesmas realizado pelas mulheres.

O Abacatal é uma comunidade que se diferencia das outras por ser quilombola e ter o apoio de diversas entidades governamentais como a Secretaria.de Ciência, Tecnologia e Meio Ambiente (SECTAM), Empresa de Assistência Técnica e Extensão Rural do Estado do Pará (EMATER-PA), Companhia de Desenvolvimento da Área Metropolitana de Belém (CODEM/PA) e não-governamentais como o Programa Pobreza e Meio Ambiente na Amazônia (POEMA), desenvolvendo trabalhos que vão desde a aceitação da própria raça e combate ao racismo, até o incentivo para a plantação de fruteiras como o cupuaçu e a acerola e para a criação de galinha caipira, buscandose melhorar a economia local. Atualmente sua economia está baseada na produção de carvão, comercializado nas feiras de Ananindeua e Belém, PA.

\section{CONCLUSÕES}

Este estudo reflete a necessidade de elaboração de medidas mitigadoras quanto ao uso dos recursos naturais pelas comunidades locais e do entorno do Parque Ecoturístico do Guamá. Constituem-se numa preocupação notória dos moradores, os efeitos que a Alça Rodoviária de Belém irá provocar sobre tais recursos ao longo dos anos.

Em todas as comunidades, os entrevistados observaram que houve grande diminuição dos recursos da fauna e flora, de um passado recente até os dias atuais, mas não há nenhum projeto ou programa que enfoque o desenvolvimento sustentável nessas comunidades, excetuando-se a comunidade do Abacatal que tem procurado se organizar e buscar parcerias.

As espécies da fauna são caçadas para servirem como fonte de proteína e de complementação de renda, através da realização do tráfico sob encomenda, além do uso e comércio de espécies e produtos, com fins terapêuticos e afetivos ("xerimbabo").

O extrativismo de espécies madeireiras, frutíferas e medicinais também é realizado com o objetivo de subsistência, havendo apenas a comercialização do carvão e o início de um projeto de produção de mudas de frutíferas em uma comunidade.

A situação fundiária é precária pela falta de regularização da terra e ficou mais fragilizada com a construção da estrada, em função do aumento da especulação imobiliária, o que favorece o êxodo rural. 


\section{RECOMENDAÇÕES}

Elaboração de programas de Educação Ambiental nas escolas, associaçôes comunitárias e campanhas nas estradas e demais locais de fluxo estratégico do público-alvo.

Criação ou fortalecimento de programas de capacitação de pessoal para atuação nas comunidades: policiais, fiscais e agentes ambientais; agentes comunitários; técnicos em assistência social e tecnológica, etc.

Elaboração e implantação de projetos de sistemas agroflorestais, principalmente enfocando os quintais agroflorestais, objetivando a geração de alternativas para a melhoria da renda $\mathrm{e}$ da qualidade de vida, com o aquecimento da economia local em bases sustentáveis, minimizando os riscos do êxodo rural.

Fortalecimento das Associaçōes Comunitárias e das parcerias com instituiçôes ambientais e de fomento ao desenvolvimento local.

\section{BIBLIOGRAFIA CITADA}

Bahri, S. 2000. Do extrativismo aos sistemas agroflorestais. In: A floresta em jogo. O extrativismo na Amazônia central. Editora científica Laure Emperaire. Editora UNESP: Imprensa Oficial do Estado. São Paulo. p. 167-176.

Bodmer, R. E.; Penn Jr., J. 1997 Manejo da Vida Silvestre em Comunidades na Amazônia. In: Valladares-Pádua, C. R.E. Manejo e Conservação da Vida Silvestre no Brasil. CNPq. Belém. p. 52-69.

Dourojeanni. M.J. 1985. Over-exploited and Over-used Animals in the Amazon. In: Amazonia (Key environments). Eds. Prance. G.T. e Lovejoy. T.E.: Pergamon Press Ltd., 1o ed., cap. 22. p. 419-433.
Elabras, R.B. 2002. Operações de repressão aos crimes ambientais: procedimentos e resultados. In: Animais Silvestres: vida à venda. Dupligráfica. Brasília. p. 77-88.

Fang; O.L. Montenegro; R. Bodmer. 1999. Manejo y conservacion de fauna silvestre em América Latina. Bolívia: Editorial Instituto de Ecología, 496p. p. 83-108.

Jonhs, A.D.; Skorupa. J.P. 1987. Reponses of rainforest primates to habitat disturbance: a review. International Journal of Primatology, 8(2): 157-191.

King, F.W. 1999. Es posible el uso sustentable de la fauna silvestre si éste depende de um mercado externo? In: Fang, T.G.; Montenegro, O.L.; Bodmer, R. Manejo y conservacion de fauna silvestre em América Latina. Bolívia: Editorial Instituto de Ecología. p. 37-40.

Lameira, O. 2004. Uso das plantas medicinais é incentivado. In: Banco de Notícias. (www.embrapa.br) Acesso: 22/10/04.

Palha, M.D.C; Sardinha, A. S. A.; Ribeiro, D.J.; Hamoy, M.; Tourinho,M.M. 1999. Levantamento de fauna silvestre em duas comunidades de várzea da Amazônia Oriental. In: P. G. Fang; O. L. Montenegro; R. Bodmer. Manejo y conservacion de fauna silvestre em América Latina. Bolívia: Editorial Instituto de Ecología. p. 83-108.

Peres. C.A.: 1990. Effects of hunting on western Amazonian primates communities Biological Conservation, 54: 475p.

Shanley, P.; Cymerys, M.; Galvão, J. 1998. Frutiferas da Mata na Vida Amazônica. CNPq. Belém. 127pp.

Recebido em 10/10/2006

Aceito em 10/05/2007 